University of Nebraska - Lincoln

DigitalCommons@University of Nebraska - Lincoln

\title{
Highly resolved absolute cross-sections for dissociative electron attachment to SF5CF3
}

\author{
K. Graupner \\ Queen's University \\ L. M. Graham \\ Queen's University \\ T. A. Field \\ Queen's University \\ Christopher A. Mayhew \\ University of Birmingham, c.mayhew@bham.ac.uk \\ Ilya I. Fabrikant \\ University of Nebraska-Lincoln, ifabrikant@unl.edu \\ See next page for additional authors
}

Follow this and additional works at: https://digitalcommons.unl.edu/physicsfabrikant

Part of the Physics Commons

Graupner, K.; Graham, L. M.; Field, T. A.; Mayhew, Christopher A.; Fabrikant, llya I.; Miller, T. M.; Braun, M.; Ruf, M.-W.; and Hotop, Harmut, "Highly resolved absolute cross-sections for dissociative electron attachment to SF5CF3" (2008). Ilya Fabrikant Publications. 5.

https://digitalcommons.unl.edu/physicsfabrikant/5

This Article is brought to you for free and open access by the Research Papers in Physics and Astronomy at DigitalCommons@University of Nebraska - Lincoln. It has been accepted for inclusion in llya Fabrikant Publications by an authorized administrator of DigitalCommons@University of Nebraska - Lincoln. 


\section{Authors}

K. Graupner, L. M. Graham, T. A. Field, Christopher A. Mayhew, Ilya I. Fabrikant, T. M. Miller, M. Braun, M.-W. Ruf, and Harmut Hotop 


\title{
Highly resolved absolute cross-sections for dissociative electron attachment to $\mathrm{SF}_{5} \mathrm{CF}_{3}$
}

\author{
K. Graupner ${ }^{\mathrm{a}}$, L.M. Graham ${ }^{\mathrm{a}}$, T.A. Field ${ }^{\mathrm{a}}$, C.A. Mayhew ${ }^{\mathrm{b}}$, I.I. Fabrikant ${ }^{\mathrm{c}}$, \\ T.M. Miller ${ }^{\mathrm{d}}$, M. Braun ${ }^{\mathrm{e}}$, M.-W. Ruf ${ }^{\mathrm{e}}$, H. Hotop ${ }^{\mathrm{e}, *}$ \\ a Department of Physics and Astronomy, Queen's University, Belfast BT7 1NN, UK \\ b School of Physics and Astronomy, University of Birmingham, Birmingham B15 2TT, UK \\ ${ }^{c}$ Department of Physics and Astronomy, University of Nebraska, Lincoln, NE 68588-0111, USA \\ d Air Force Research Laboratory, Hanscom Air Force Base, Bedford, MA 01731-3010, USA \\ e Fachbereich Physik, Technische Universität Kaiserslautern, D-67653 Kaiserslautern, Germany
}

\section{A R T I C L E I N F O}

\section{Article history:}

Received 31 March 2008

Received in revised form 14 May 2008

Accepted 19 May 2008

Available online 27 May 2008

\section{Keywords:}

Electron attachment

Cross-section

Branching ratio

R-matrix calculation

$\mathrm{SF}_{5} \mathrm{CF}_{3}$

\begin{abstract}
A B S T R A C T
Using two complementary experimental methods, we have measured partial (mass-resolved) crosssections for dissociative electron attachment to the molecule trifluoromethyl sulfurpentafluoride $\left(\mathrm{SF}_{5} \mathrm{CF}_{3}\right)$ at the gas temperature $T_{\mathrm{G}}=300 \mathrm{~K}$ over a broad range of electron energies $(E=0.001-12 \mathrm{eV})$. The absolute scale for these cross-sections was obtained with reference to the thermal $(T=300 \mathrm{~K})$ rate coefficient for anion formation $\left(8.0(3) \times 10^{-8} \mathrm{~cm}^{3} \mathrm{~s}^{-1}\right)$. Below $1 \mathrm{eV}, \mathrm{SF}_{5}-$ is the dominant product anion and formed through the lowest anion state which cuts the neutral $\mathrm{SF}_{5} \mathrm{CF}_{3}$ potential close to the $\mathrm{S}-\mathrm{C}$ equilibrium distance. The highly resolved laser photoelectron attachment data exhibit a downward Wigner cusp at $86 \mathrm{meV}$, indicating that the $v_{4}\left(a_{1}\right)$ vibrational mode is important for the primary attachment dynamics. Both $\mathrm{SF}_{5}{ }^{-}$and $\mathrm{F}^{-}$anions are formed with similar yields through the first excited resonance located near $3.6 \mathrm{eV}$. Towards higher energies, the anions $\mathrm{CF}_{3}{ }^{-}, \mathrm{SF}_{4}{ }^{-}$, and $\mathrm{SF}_{3}{ }^{-}$are also produced. Summation of the partial cross-sections yields a total absolute cross-section for anion formation over the energy range $0.001-12 \mathrm{eV}$. This is used to calculate the dependence of the rate coefficient for dissociative electron attachment over a broad range of electron temperatures for the fixed gas temperature $T_{\mathrm{G}}=300 \mathrm{~K}$; good agreement is found between the calculated values and those obtained in a drift tube experiment. In addition to the experimental work, semiempirical R-matrix calculations have been carried out for the energy dependence of the cross-section for $\mathrm{SF}_{5}{ }^{-}$formation. The experimental findings are semi-quantitatively recovered.
\end{abstract}

(c) 2008 Elsevier B.V. All rights reserved.

\section{Introduction}

An analysis of stratospheric air samples by Sturges et al. [1] has indicated that trifluoromethyl sulfurpentafluoride $\left(\mathrm{SF}_{5} \mathrm{CF}_{3}\right)$ is present in the stratosphere. The compound is thought to be exclusively anthropogenic in origin; it has been speculated that the source of atmospheric $\mathrm{SF}_{5} \mathrm{CF}_{3}$ may be the reaction of $\mathrm{SF}_{6}$ with fluoropolymers in electrical devices (see papers by Huang et al. [2] and by Tsai $[3,4]$ ). Although present at a level of only $0.12 \mathrm{ppt}$ in 1999 , the atmospheric abundance of $\mathrm{SF}_{5} \mathrm{CF}_{3}$ is reportedly increasing by $6 \%$ per year, tracking the increase of atmospheric $\mathrm{SF}_{6}$ [1]. This is significant because both $\mathrm{SF}_{6}$ and $\mathrm{SF}_{5} \mathrm{CF}_{3}$ are powerful greenhouse

\footnotetext{
* Corresponding author at: Fachbereich Physik, Technische Universität Kaiserslautern, P.O. Box 3049, D-67653 Kaiserslautern, Germany.

E-mail address: hotop@physik.uni-kl.de (H. Hotop).
}

gases. The global warming potential (GWP) of $\mathrm{SF}_{5} \mathrm{CF}_{3}$ is currently estimated at 18,500 times that of $\mathrm{CO}_{2}[5,6]$, greater than almost any other molecule. The stratospheric profile that was measured by Sturges et al. suggests this compound is long-lived in the atmosphere. Kennedy and Mayhew [7] have recently speculated that, because the compound is not broken down by UV photodissociation, and there are no known atmospheric sinks, ion-molecule reactions and electron attachment reactions must play a significant role in the atmospheric chemistry of $\mathrm{SF}_{5} \mathrm{CF}_{3}$. Previous reports on the electron attachment rate to $\mathrm{SF}_{5} \mathrm{CF}_{3}$ place an upper limit of approximately 1000 years on the compound's atmospheric lifetime [7-10]. In addition to its atmospheric relevance, electron attachment studies to $\mathrm{SF}_{5} \mathrm{CF}_{3}$ are of interest because of the comparisons we can make with $\mathrm{SF}_{6}$, a molecule used in many technological applications [11,12], and with the similar molecule $\mathrm{SF}_{5} \mathrm{Cl}$ for which we recently reported a comprehensive set of partial cross-sections for anion formation [13]. 
The findings of Sturges et al. [1] initiated several other studies, including IR spectroscopy [14,15], swarm experiments on electron attachment $[7,8,16]$, and electron beam measurements of the partial cross-sections for anion formation [17,18]. The latter two studies - following pioneering work on the total attachment cross-section for this molecule by Chen et al. [19] - agreed in the observation that the dominant anion at low energies is $\mathrm{SF}_{5}{ }^{-}$while the respective findings for other anions were contradictory. Sailer et al. [17] reported a band for $\mathrm{CF}_{3}$ - formation with a peak cross-section of $0.35 \times 10^{-20} \mathrm{~m}^{2}$ at $1.2 \mathrm{eV}$ and a band for $\mathrm{F}^{-}$production peaking at about $0.9 \mathrm{eV}$ (cross-section $0.08 \times 10^{-20} \mathrm{~m}^{2}$ ) (in addition a weaker maximum at near-zero energies was seen in the $\mathrm{F}^{-}$yield). Balog et al. [18] investigated low-energy electron collisions with free $\mathrm{SF}_{5} \mathrm{CF}_{3}$ molecules and with $\mathrm{SF}_{5} \mathrm{CF}_{3}$ in homogeneous clusters and in nanofilms. Like Sailer et al., they reported anion yield functions for the fragments $\mathrm{SF}_{5}{ }^{-}, \mathrm{F}^{-}$, and $\mathrm{CF}_{3}{ }^{-}$with relative maximum yields of 1000,4 , and 0.03 while the Innsbruck experiment [17] gave respective maximum yields of $1000,0.7$, and 4 . The Berlin measurement for $\mathrm{F}^{-}$production [18] showed a broad band peaking at about $0.5 \mathrm{eV}$ and a substantially weaker and rather wide band around $3.2 \mathrm{eV}$; their results for $\mathrm{CF}_{3}-$ formation indicate the presence of a rather narrow peak near zero energy and a broad band around $3.5 \mathrm{eV}$.

In the present work, we combine the results from two different beam experiments to determine the partial and the total absolute cross-sections for dissociative electron attachment (DEA) to $\mathrm{SF}_{5} \mathrm{CF}_{3}$ over the energy range $0.001-12 \mathrm{eV}$. At energies below $1 \mathrm{eV}$, the $\mathrm{SF}_{5}{ }^{-}$anion is the dominant product, and we measure its DEA cross-section by two versions of the laser photoelectron attachment (LPA) method (LPA and extended laser photoelectron attachment (EXLPA), see Section 2.1) over the range 0.001-1.66 eV with energy widths of $2 \mathrm{meV}$ (LPA) and about $25 \mathrm{meV}$ (EXLPA). The LPA data are put on an absolute cross-section scale with reference to the well-known thermal $(T=300 \mathrm{~K})$ DEA rate coefficient. The other experiment uses a pulsed electron source from a trochoidal electron monochromator with moderate resolution and a timeof-flight mass spectrometer. It yields simultaneously measured relative cross-sections for the relevant product anions with little mass and kinetic energy discrimination over the range $0.2-12 \mathrm{eV}$. The two sets of cross-section data are combined and thus yield the partial and total cross-sections for anion formation.

The paper is organized as follows: in Section 2, we describe the two experimental setups. In Section 3, we summarize some of the relevant structural and energetic properties of $\mathrm{SF}_{5} \mathrm{CF}_{3}$ and its anion, and we describe briefly the R-matrix method used to calculate the energy dependence of the DEA cross-section at low energies $(<1 \mathrm{eV})$. In Section 4, we report the partial and total crosssections and compare with the calculated cross-section and with the previous experimental results [17-19]. In addition, we calculate the dependence of the DEA rate coefficient on electron temperature for a Maxwellian electron gas at the fixed gas temperature $T_{\mathrm{G}}=300 \mathrm{~K}$ and compare with a previous drift tube experiment [7]. We conclude with a brief summary.

\section{Experimental}

\subsection{Laser photoelectron attachment experiment (Kaiserslautern)}

In order to measure highly resolved cross-sections for anion formation in low-energy electron collisions with $\mathrm{SF}_{5} \mathrm{CF}_{3}$, we used two variants of the laser photoelectron attachment method, as discussed elsewhere in detail [20-22]. The energy range 1-200 meV was covered at resolutions of about $2 \mathrm{meV}$ by the standard LPA method [20]: energy-variable photoelectrons (typical current $40 \mathrm{pA}$ ) are created in the reaction region with the target gas by resonant two-color photoionization of ground state potassium atoms via the excited $K\left(4 p_{3 / 2}\right)$ level [21]. Higher electron energies were accessed by the extended laser photoelectron attachment method [22]: here near-zero energy photoelectrons are produced in an auxiliary photoionization chamber (distance from reaction centre about $5 \mathrm{~cm}$ ), accelerated by a weak electric field in a guiding magnetic field $(0.002 \mathrm{~T})$, brought to the energy of interest prior to traversal through the target region, and subsequently accelerated and deflected onto a collector plate. Care was taken to align the exciting and the focused ionizing laser (diameter $0.12 \mathrm{~mm}$ ) to avoid any collisions of the electron beam with surfaces on its way from the photoionization chamber to the collector since these would yield spurious low-energy electrons and thus lead to unwanted attachment processes. This is especially critical in energy ranges where the attachment cross-section is small. In this way, the drop of the $\mathrm{SF}_{6}{ }^{-}$cross-section, for example, could be followed over five orders of magnitude towards higher electron energies [22]. The effective resolution in the EXLPA experiment was about $25 \mathrm{meV}$.

Both the LPA and the EXLPA experiment were pulsed at a rate of $100 \mathrm{kHz}$ : following each photoelectron production and attachment period, the infrared laser $(767 \mathrm{~nm})$, exciting the $\mathrm{K}\left(4 \mathrm{~s}-4 \mathrm{p}_{3 / 2}\right)$ transition, was switched off by an acousto-optical modulator, and a voltage pulse was initiated to extract the anions. A stack of electrodes imaged the anions onto the entrance hole of a quadrupole mass filter which mass selected the species of interest. The transmitted anions were detected by a channel electron multiplier (Fa. Sjuts, background $0.02 \mathrm{~s}^{-1}$ ).

A diffuse low-density target of $\mathrm{SF}_{5} \mathrm{CF}_{3}$ molecules (Apollo Scientific, Ltd., stated purity $99 \%$ ) at the gas temperature $T_{\mathrm{G}}=300 \mathrm{~K}$ was used without further purification. An anion mass spectrum taken at very low electron energies (using electron transfer from highly excited $K^{* *}(n d)$ Rydberg atoms with $n \approx 140$; see, e.g., [21]) yielded $\mathrm{SF}_{5}{ }^{-}$as the dominant anion product. $\mathrm{SF}_{6}{ }^{-}$anions were detected at a relative intensity level of about 3.5\% and attributed to a minor $\mathrm{SF}_{6}$ impurity (relative density about $1 \%$ ); correspondingly, $\mathrm{SF}_{5}{ }^{-}$anions resulting from $\mathrm{DEA}$ to $\mathrm{SF}_{6}$ contribute to the $\mathrm{SF}_{5}{ }^{-}$yield at a negligible level (see Ref. [22] for the energy dependent cross-section for $\mathrm{SF}_{5}{ }^{-}$formation from $\mathrm{SF}_{6}$ ). Other anions in the mass spectrum had intensities $\leq 10^{-4}$ relative to that for $\mathrm{SF}_{5}{ }^{-}$.

The LPA/EXLPA experiment provides a highly resolved yield $Y(E)$ for anion formation. This yield is proportional to the absolute DEA cross-section, i.e., $\sigma(E)=N Y(E)$ where $N$ is a normalization factor, assumed to be independent of electron energy $E$. The size of the normalization factor is established with reference to a known thermal DEA rate coefficient for the same process. The thermal rate coefficient $k=\left\langle v_{\text {rel }} \sigma\left(v_{\text {rel }}\right)\right\rangle, \quad\left(v_{\text {rel }}=\right.$ relative collision velocity of the electron-molecule system) is given by the average:

$k\left(T_{\mathrm{e}}, T_{\mathrm{G}}\right)=(2 / \mathrm{m})^{1 / 2} \int E^{1 / 2} \sigma_{\text {tot }}\left(E ; T_{\mathrm{G}}\right) f\left(E ; T_{\mathrm{e}}\right) \mathrm{d} E$

Here, $T_{\mathrm{G}}$ denotes the rovibrational temperature of the target gas, $T_{\mathrm{e}}$ the electron temperature and $f\left(E ; T_{\mathrm{e}}\right)$ the electron distribution function. Note that the velocity of the gas molecules at $T_{\mathrm{G}}=300 \mathrm{~K}$ is much smaller than the electron velocity even at electron energies as low as $0.1 \mathrm{meV}$, and the relative collision velocity $v_{\text {rel }}$ can be replaced by the electron velocity. In calculating the rate coefficient, we use a Maxwellian distribution function which is given by

$f\left(E ; T_{\mathrm{e}}\right)=2\left(\frac{E}{\pi}\right)^{1 / 2} \beta^{-3 / 2} \exp \left(-\frac{E}{\beta}\right)$

with $\beta=k_{\mathrm{B}} T_{\mathrm{e}}\left(k_{\mathrm{B}}=\right.$ Boltzmann constant). The usual thermal average in Eq. (1) requires $T_{e}=T_{G}$. In the calibration of the absolute DEA cross-section scale, we have used the thermal rate coefficient $k(T)$ measured for $T=T_{\mathrm{e}}=T_{\mathrm{G}}=300 \mathrm{~K}$. 
2.2. Trochoidal electron monochromator time-of-flight (TEM-TOF) experiment (Belfast)

The DEA experiments at Belfast used a trochoidal electron monochromator in combination with a time-of-flight mass spectrometer. The apparatus has been described before in some detail [23], and only the essentials are summarized here. The electron beam path is immersed in a parallel guiding magnetic field of $0.008 \mathrm{~T}$. A deflection plate in the beam-monitoring Faraday cup moves the electrons off-axis and thus prevents return of the electrons to the interaction region. The electron energy was set by floating the electron gun potentials relative to the interaction region. A plate near the filament is pulsed to send short (duration about $1 \mu \mathrm{s}$ ) pulses of electrons through the interaction region. After the electrons have left the interaction region, a repeller plate is pulsed to push the product anions from the source region. Ions pass into the acceleration region of the TOF mass spectrometer where they are further accelerated before they pass through the field-free drift region and strike the multichannel plate detector. The repetition rate of this pulse scheme is $12 \mathrm{kHz}$. The apparatus is operated under conditions where at most one ion is detected per 10 cycles to minimize any paralysis of the detector due to the arrival of two ions at the same time. The electron energy resolution (full width at half maximum) was estimated from the width of the apparent $\mathrm{SF}_{6}{ }^{-}$yield due to electron attachment to $\mathrm{SF}_{6}$ at near-zero energies and amounted to $0.25-0.37 \mathrm{eV}$.

The experiment was carried out at room temperature $\left(T_{\mathrm{G}}=300 \mathrm{~K}\right.$. The gas pressure in the interaction region was varied between about $5 \times 10^{-6}$ and $5 \times 10^{-5}$ mbar, which corresponds to number densities in the $10^{11}$ molecules $\mathrm{cm}^{-3}$ range. Spectra were measured at different pressures so that any collisional second order processes could be identified; all signals were found to be linear with pressure and no evidence for collisional effects was found. The target gas $\mathrm{SF}_{5} \mathrm{CF}_{3}$ was provided by Fluorochem Ltd. and used without further purification. From the mass spectra, taken near zero electron energy, we conclude that the maximum concentration of any $\mathrm{SF}_{6}$ impurity was $0.2 \%$.

\section{Basic molecular information and R-matrix calculations}

\subsection{Structural and energetical aspects of anion formation in electron attachment to $\mathrm{SF}_{5} \mathrm{CF}_{3}$}

In Fig. 1 we present simplified potential energy curves for $\mathrm{SF}_{5}+\mathrm{CF}_{3}$ and $\mathrm{SF}_{5}{ }^{-}+\mathrm{CF}_{3}$, relevant for the dominant fragmentation channel in DEA to $\mathrm{SF}_{5} \mathrm{CF}_{3}$ at low energies. Parameters for these potential curves (see Section 3.2) were obtained from G3(MP2) calculations, which represent an improvement over earlier G2(MP2) ones [8]. The G3(MP2) compound method of Curtiss et al. [24], which approximates a quantum configuration interaction $(\mathrm{QCISD}(\mathrm{T}))$ calculation with a large basis set, was used as implemented in the Gaussian-03W program [25]. An important quantity for DEA to $\mathrm{SF}_{5} \mathrm{CF}_{3}$ is its dissociation energy into the fragments $\mathrm{SF}_{5}+\mathrm{CF}_{3}$; photon-induced fluorescence studies by Ruiz et al. [26] recently yielded an upper limit estimate of $3.9(3) \mathrm{eV}$. The G3(MP2) value is $3.12 \mathrm{eV}$ and compatible with the upper limit. The calculations give the dissociation energy of the anion to the fragments $\mathrm{SF}_{5}{ }^{-}+\mathrm{CF}_{3}$ as $0.26 \mathrm{eV}(0 \mathrm{~K})$ and the adiabatic electron affinity (EA) for $\mathrm{SF}_{5} \mathrm{CF}_{3}$ as $1.37 \mathrm{eV}$. Moreover, they provide the value $\mathrm{EA}\left(\mathrm{SF}_{5}\right)=4.07 \mathrm{eV}$, which places the asymptote of $\mathrm{SF}_{5}{ }^{-}+\mathrm{CF}_{3} 1.11 \mathrm{eV}$ below the vibrational ground state of $\mathrm{SF}_{5} \mathrm{CF}_{3}$. Recent information on the dynamics and energetics of anion formation from electron attachment to $\mathrm{SF}_{6}$ suggested that $\mathrm{SF}_{5}{ }^{-}$formation is endothermic by $0.41 \mathrm{eV}$ [27]; combining this value with the dissociation

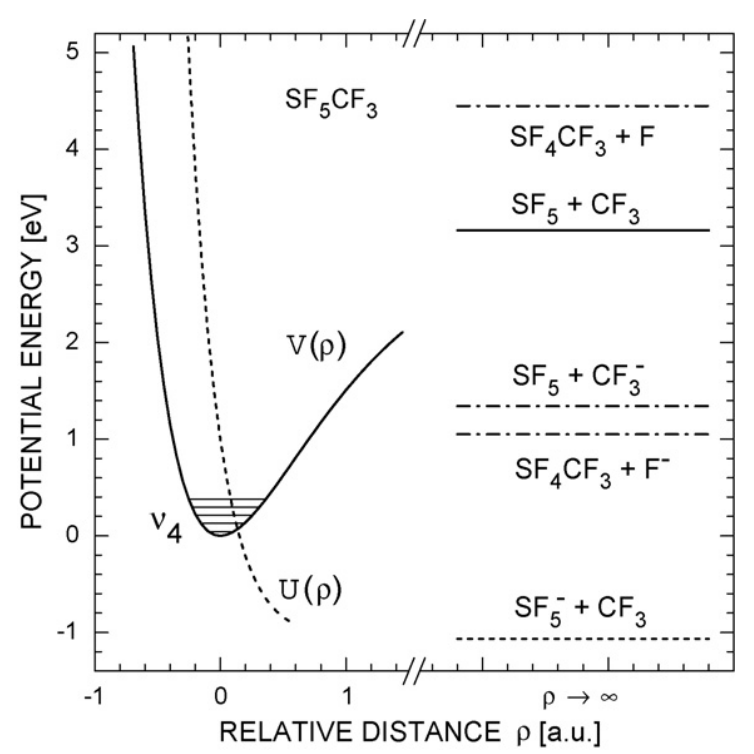

Fig. 1. Simplified potential energy curves for $\mathrm{SF}_{5} \mathrm{CF}_{3}$ and its anion. Note that the relative distance scale represents different normal coordinates depending on the symmetries and dissociation limits.

energy $D\left(\mathrm{SF}_{5}-\mathrm{F}\right)=4.35(10) \mathrm{eV}$ due to Tsang and Herron [28] yields $\mathrm{EA}\left(\mathrm{SF}_{5}\right)=3.94 \mathrm{eV} . \mathrm{SF}_{5}-$ formation from $\mathrm{SF}_{5} \mathrm{CF}_{3}$ is thus an exothermic process with a $\mathrm{Q}$ value of about $1 \mathrm{eV}$. In contrast, $\mathrm{CF}_{3}{ }^{-}$formation is an endothermic process. Using $\mathrm{EA}\left(\mathrm{CF}_{3}\right)=1.82(5) \mathrm{eV}$ [29] and the $\mathrm{G} 3(\mathrm{MP} 2)$ value for $D_{0}\left(\mathrm{SF}_{5}-\mathrm{CF}_{3}\right)$ (see above), the endothermicity for $\mathrm{CF}_{3}{ }^{-}$formation is estimated to be $1.3 \mathrm{eV}$. Likewise, $\mathrm{F}^{-}$formation from $\mathrm{SF}_{5} \mathrm{CF}_{3}$ is an endothermic process. The $\mathrm{G} 3(\mathrm{MP} 2)$ calculations give $D_{0}\left(\mathrm{~F}-\mathrm{SF}_{4} \mathrm{CF}_{3}\right)=4.45 \mathrm{eV}$ for the weakest $\mathrm{F}$ bond (an equatorial $\mathrm{S}-\mathrm{F}$ bond), comparable to that for $\mathrm{SF}_{6}$. With the known value $\mathrm{EA}(\mathrm{F})=3.401 \mathrm{eV}$ [30], one obtains an endothermicity of about $1 \mathrm{eV}$ for $\mathrm{F}^{-}$formation from $\mathrm{SF}_{5} \mathrm{CF}_{3}$. Molecular geometries, energies, and frequencies are available on the journal's website as supplementary information.

For DEA calculations (see Section 3.2) it is necessary to identify the vibrational mode of $\mathrm{SF}_{5} \mathrm{CF}_{3}$, corresponding most closely to the $\mathrm{SF}_{5}-\mathrm{CF}_{3}$ reaction coordinate. The first vibrational mode analysis, based on the measured infrared spectrum for $\mathrm{SF}_{5} \mathrm{CF}_{3}$, was performed by Eggers et al. [31]. They assumed that the barrier for the internal rotation of the $\mathrm{CF}_{3}$ group is low and accordingly classified vibrational modes in terms of the $C_{4 \mathrm{~V}}$ symmetry representations. They identified the modes corresponding to internal vibrations in $\mathrm{CF}_{3}$ (type I), modes corresponding to internal vibrations in $\mathrm{SF}_{5}$ (type II), and the modes corresponding to the motion of $\mathrm{SF}_{5}$ relative to $\mathrm{CF}_{3}$ (type III).

The strongest modes of type I are $v_{1}\left(a_{1}\right), v_{11}(e)$, and $v_{3}\left(a_{1}\right)$, of type II $v_{2}\left(a_{1}\right), v_{4}\left(a_{1}\right)$, and $v_{5}\left(a_{1}\right)$. They observed two modes of type III, $v_{16}(e)$ and $v_{17}(e)$, but could not identify the S-C stretch mode $v_{6}\left(a_{1}\right)$ which is of most interest to us. By comparing the spectrum of $\mathrm{SF}_{5} \mathrm{CF}_{3}$ with those of $\mathrm{C}_{2} \mathrm{~F}_{6}$ and $\mathrm{S}_{2} \mathrm{~F}_{10}$ they estimated the frequency of $v_{6}$ as $300 \mathrm{~cm}^{-1}$. This agrees rather well with the result of present $\mathrm{MP2}(\mathrm{FC}) / 6-31 \mathrm{G}(\mathrm{d})$ calculations which give the frequency of this mode as $316 \mathrm{~cm}^{-1}$.

There are several more recent measurements $[1,5,14,15]$ of the infrared spectrum of $\mathrm{SF}_{5} \mathrm{CF}_{3}$. Nielsen et al. [14] as well as Rinsland et al. [15] detected, but did not discuss a rather weak absorption band around $690 \mathrm{~cm}^{-1}$ which can be attributed to what Eggers et al. identified as the $v_{4}\left(a_{1}\right)=1$ excitation $\left(692 \mathrm{~cm}^{-1}=85.8 \mathrm{meV}\right)$ [31]. In a recent theoretical paper $\mathrm{Li}$ et al. [32] treated the electronic structure of $\mathrm{SF}_{5} \mathrm{CF}_{3}$ by the DFT method and performed a vibrational frequency analysis. They concluded that the barrier for the torsional 
motion is low (about $1.5 \times 10^{-4}$ a.u.) and therefore the $\mathrm{CF}_{3}$ group is predicted to rotate freely at room temperature. This justifies the $C_{4 \mathrm{~V}}$ symmetry assumption employed by Eggers et al. [31]. On the other hand, Li et al. [32] present only seven vibrational frequencies and do not classify them in terms of symmetry species. Interestingly, they identify the frequency $746 \mathrm{~cm}^{-1}$ as corresponding to the $\mathrm{S}-\mathrm{C}$ stretch. Since DFT calculations tend to overestimate frequencies, the true values may be more like $690 \mathrm{~cm}^{-1}$, rather close to the spectroscopy frequency of the $v_{4}\left(a_{1}\right)$ mode. As will be discussed below, the LPA experiment exhibits a distinct Wigner cusp at the onset for excitation of one quantum of the $v_{4}\left(a_{1}\right)$ vibration, indicating that this mode is important for the primary electron attachment process.

Although for definite conclusions about the mechanism for electron attachment to $\mathrm{SF}_{5} \mathrm{CF}_{3}$ an analysis of the multidimensional potential energy anion surface is necessary, the cusp at the threshold for $\Delta v_{4}=1$ vibrational excitation allows us to assume that, similar to the process of electron attachment to $\mathrm{SF}_{6}$, the electron capture initially drives the symmetric $\mathrm{S}-\mathrm{F}$ stretch vibrational mode $v_{4}$, and then due to the process of intramolecular vibrational energy redistribution (IVR), the excess energy is channeled into the $\mathrm{S}-\mathrm{C}$ stretch which eventually leads to the dissociation into the fragments $\mathrm{SF}_{5}{ }^{-}$and $\mathrm{CF}_{3}$. We will assume that the anion state is stabilized rapidly, before the IVR process becomes operative, and therefore the attachment process can be treated in a onedimensional approximation, assuming coupling of the anion state with only the $v_{4}$ mode. This approach is similar to our effectiverange-theory treatment of electron attachment to $\mathrm{SF}_{6}$ [33].

\subsection{R-matrix calculations of the DEA cross-section for $\mathrm{SF}_{5}{ }^{-}$ formation}

With the aim to provide some insight into the electron attachment process we have carried out semiempirical R-matrix calculations of the DEA cross-sections. In accord with our assumption about the dominance of the $v_{4}$ mode at the electron capture stage, we represent the neutral molecule by an effective one-dimensional potential energy curve generating the correct quantum of the $v_{4}$ vibration, $\omega\left(v_{4}\right)=85.8 \mathrm{meV}$. Vibrational frequencies were calculated using the Hartree-Fock, density functional theory, and MP2. We use the corresponding reduced mass $(M=17.353 \mathrm{u})$ for the $v_{4}$ motion but adopt, however, the experimental value of the $v_{4}$ frequency. Since the asymptotic value of the neutral energy along the $v_{4}$ coordinate is not relevant to the DEA process under consideration, we have chosen, rather arbitrarily, for the dissociation energy its value along the $\mathrm{S}-\mathrm{C}$ reaction coordinate, $3.09 \mathrm{eV}$. This choice is not consistent, of course, with the onedimensional model. We should emphasize, however, that in the present case only the coupling of the anion state with the first few vibrational states of the $v_{4}$ mode is important for the DEA dynamics. Additional calculations using different dissociation energies, but the same vibrational frequency yielded practically the same results. Using the input data described above, we parameterize the neutral curve in the Morse form:

$V(\rho)=A[\exp (-a \rho)-1]^{2}$

where $\rho=R-R_{\mathrm{e}}$ is the normal $v_{4}$ coordinate relative to the equilibrium separation $R_{\mathrm{e}}, A=3.13 \mathrm{eV}$ and $a=1.1853 a_{0}^{-1} \quad\left(a_{0}=\mathrm{Bohr}\right.$ radius $=52.9 \mathrm{pm}$ ). The anion curve is parameterized in the form:

$U(\rho)=B \exp (-2 b \rho)-C \exp (-b \rho)+D$

The asymptotic value of the anion curve $D$ was obtained from the calculated [8] adiabatic electron affinity of $\mathrm{SF}_{5} \mathrm{CF}_{3}, 1.235 \mathrm{eV}$ and the dissociation energy of the anion, $0.26 \mathrm{eV}$, resulting in $D=-0.975 \mathrm{eV}$. All other parameters were considered as empirical.
The R-matrix surface amplitude $\gamma(\rho)$ which determines the resonance width $[34,35]$ was parameterized in the form:

$\gamma(\rho)=\frac{\gamma_{0}}{\exp (\zeta \rho)+\eta}$

where $\gamma_{0}, \zeta$ and $\eta$ are fit parameters. Typically, $\gamma(\rho)$ is a slowly varying function, and its value between the equilibrium separation $(\rho=0)$ and the crossing point between the neutral and the anion potential curves determines the absolute magnitude of the DEA cross-section. The parameters employed in our calculations are $b=1.972 a_{0}^{-1}, B=2.57 \mathrm{eV}, C=0.60 \mathrm{eV}, \gamma_{0}=0.222\left(a_{0} \times \text { Hartree }\right)^{1 / 2}$ ( 1 Hartree $=27.211 \mathrm{eV}), \zeta=2.330 a_{0}^{-1}$, and $\eta=0.1725$. The vibrational motion for the calculation of the DEA cross-sections was included using the quasi-classical approximation of the R-matrix theory $[35,36]$. To couple the resonant anion state with the electron continuum, we calculate the electron wave functions in electron scattering channels. For these calculations we have employed the dipole moment of $\mathrm{SF}_{5} \mathrm{CF}_{3}, \mu=0.384 \mathrm{D}$ [37] and the polarizability $\alpha=8.5 \times 10^{-30} \mathrm{~m}^{3}$, as estimated by us.

\section{Results and discussion}

\subsection{Highly resolved absolute cross-section for $\mathrm{SF}_{5}{ }^{-}$formation}

In agreement with the earlier work [17,18], both the LPA and the TEM-TOF experiments confirmed that $\mathrm{SF}_{5}{ }^{-}$is by far the dominant anion formed in low-energy electron attachment to $\mathrm{SF}_{5} \mathrm{CF}_{3}$. In the following we discuss the highly resolved LPA and EXLPA results which were measured for $\mathrm{SF}_{5}{ }^{-}$over the range $0.001-1.66 \mathrm{eV}$. With reference to the thermal rate coefficient of Mayhew et al. $\left(k(300 \mathrm{~K})=8.0(3) \times 10^{-8} \mathrm{~cm}^{3} \mathrm{~s}^{-1}\right)$ [16], a reliable absolute scale was established for this partial DEA cross-section which is subsequently used to establish absolute cross-sections also for the other fragment anion channels and for total anion production.

In Fig. 2, we present the absolute DEA cross-section for $\mathrm{SF}_{5}{ }^{-}$formation from $\mathrm{SF}_{5} \mathrm{CF}_{3}$ determined in this work by combining the LPA (0.001-0.19 eV) and the EXLPA (0.19-1.66 eV) data. The energy resolution was about $2 \mathrm{meV}$ for the LPA data and about $25 \mathrm{meV}$ for the EXLPA results, respectively. The LPA anion yield was averaged over six original data points (about 6 channels per meV) and interpolated with respect to an integer meV scale; the EXLPA anion yield was measured with a channel width of $1 \mathrm{meV}$ and normalized to the LPA data in the energy range from 160 to $190 \mathrm{meV}$ where the LPA and EXLPA yields exhibited identical slopes. Below about $0.5 \mathrm{eV}$ the partial $\mathrm{SF}_{5}{ }^{-}$cross-section is identical with the total cross-section since other fragment ions do not contribute at a significant level (see below); therefore, it is possible to use the total thermal rate coefficient $k(T=300 \mathrm{~K})$ to establish the absolute cross-section scale shown in Fig. 2.

Close to $E=86 \mathrm{meV}$, a clear downward-step like Wigner cusp is observed (see especially the expanded view in Fig. 2b) which is attributed to the interaction of the primary attachment process with the channel for vibrational excitation of the $v_{4}\left(a_{1}\right)$ mode. As is known from the previous high-resolution work on molecules such as $\mathrm{SF}_{6}$ [20,22], $\mathrm{CCl}_{4}$ [38], $\mathrm{CF}_{3} \mathrm{Br}$ [39], and $\mathrm{CF}_{3} \mathrm{I}$ [40], these Wigner cusps are characteristic for the vibrational modes which are active in the attachment process. Note that for $\mathrm{SF}_{5}{ }^{-}$formation, the vibrational modes which may be considered to promote dissociation of the primary anion complex $\left(\mathrm{SF}_{5} \mathrm{CF}_{3}\right)^{-}$towards the fragments $\mathrm{SF}_{5}{ }^{-}+\mathrm{CF}_{3}$ are not identical with the channel interaction mode $v_{4}\left(a_{1}\right)$ which basically represents a symmetric internal vibration of the $\mathrm{SF}_{5}$ group. 



Fig. 2. Absolute cross-section for $\mathrm{SF}_{5}{ }^{-}$formation due to electron attachment to $\mathrm{SF}_{5} \mathrm{CF}_{3}$ (gas temperature $T_{\mathrm{G}}=300 \mathrm{~K}$ ). (a) Combined LPA/EXLPA data (open gray circles) over the range $0.001-1.66 \mathrm{eV}$, compared with the R-matrix cross-section (full curve) for energies up to $0.83 \mathrm{eV}$. Close to $E=86 \mathrm{meV}$, the measured and calculated cross-sections exhibit downward step-like structure (see also (b)) due to the interaction between the attachment and the $\Delta v_{4}=1$ vibrational excitation channel. (b) Closer view at the low-energy region $(0.5-500 \mathrm{meV}$, indicated in (a) by broken lines). The chain curve shows the extended Vogt-Wannier (EVW) cross-section, adjusted in absolute value to the experimental cross-section at $E=2 \mathrm{meV}$. The dotted, shortdash and full thin curves represent the calculated state-specific DEA cross-sections for the initial vibrational levels $v_{4}^{i}=0,1$, and 2, respectively. For further details, see text.

The observation of the cusp structure at the $\Delta v_{4}\left(a_{1}\right)=1$ vibrational onset was incorporated into our theoretical model, discussed in Section 3.2, whose results are also included in Fig. 2a and b (full curves). Good agreement between the experimental and the calculated cross-sections - including the shape of the cusp structure at the $\Delta v_{4}=1$ threshold - is observed at energies up to about $0.25 \mathrm{eV}$. The calculations also predict weaker cusps at the higher $\Delta v_{4} \geq 2$ onsets, but these features are not apparent in the measurements. Towards higher energies the calculated cross-section progressively stays above the experimental values by up to a factor two. These deviations can be removed by a different choice of the surface amplitude $\gamma(\rho)$ which, however, varies rather fast with $\rho$. We think that this reflects, in an empirical way, the complexity of the actual multidimensional surface dynamics of the DEA process.

We note that the calculated DEA cross-sections (full curves in Fig. 2a and $b$ ) represent the vibrational average with regard to the initial thermal population of the $v_{4}\left(a_{1}\right)$ mode. Since the $v_{4}$ quantum (85.8 meV [31]) is about three times larger than $k_{\mathrm{B}} T$, most of the population $(\approx 96 \%)$ resides in the initial $v_{4}^{i}=0$ ground state. The state-specific DEA cross-section for $v_{4}^{i}=1$ actually exceeds the $v_{4}^{i}=$ 0 cross-section for $E<0.23 \mathrm{eV}$ (by more than a factor of two below $E=16 \mathrm{meV}$ ) as a result of a more favourable Franck-Condon factor for the transition from the neutral to the anion state; the $v_{4}^{i}=1$ population thus leads to a non-negligible, but small contribution to the vibrationally averaged DEA cross-section. The cross-section for $v_{4}^{i}=2$ is smaller (by about a factor of three at low energies) than that for $v_{4}^{i}=0$, and its contribution to the thermal average is negligible.

At low electron energies, we compare the measured crosssection shape with the prediction of the extended Vogt-Wannier (EVW) capture model [41,42] (chain curve in Fig. 2b). In these calculations, we use the spectroscopic electric dipole moment of $0.384 \mathrm{D}$ [37] and the estimated polarizability $8.5 \times 10^{-30} \mathrm{~m}^{3}$. The predicted EVW cross-section is about a factor of three higher than the measured absolute DEA cross-section, indicating - in contrast to, e.g., the cases of $\mathrm{SF}_{6}$ or $\mathrm{CCl}_{4}[41,42]$ - that for the molecule $\mathrm{SF}_{5} \mathrm{CF}_{3}$ the efficiency for anion formation only amounts to about one third of the electron capture events. In the R-matrix description of the DEA process, the EVW cross-section behaviour is built into the theory via the long-range electron-molecule interactions. The lowering of the DEA cross-section from the EVW value is due to two effects: (i) non-optimal Franck-Condon factors for the transition from the neutral molecule to the initial temporary negative ion (TNI) state upon electron capture; (ii) a smaller than unity survival probability for the evolution of the TNI to the dissociated pair $\mathrm{SF}_{5}{ }^{-}+\mathrm{CF}_{3}$. This evolution involves IVR and thus coupling to the motion which leads to dissociation of the TNI. The processes involved in (ii) will in general depend on the initial thermal energy in the various participating vibrational modes, and this dependence can lead to the Arrhenius-type rise in the thermal $\left(T \equiv T_{\mathrm{e}}=T_{\mathrm{G}}\right)$ rate coefficient $k(T)$ (activation energy $0.025 \mathrm{eV}$ ), observed by Miller et al. [8] over the temperature range $295-563 \mathrm{~K}$. We note that the Rmatrix calculations described above yield a very weak dependence of $k(T)$ on $T$ (variation less than 3\% over the mentioned temperature range). This deviation from the experimental observations [8] is attributed to the one-dimensional approximation employed in the calculations which does not incorporate IVR and dissociation. This issue was recently discussed in some detail for DEA to $\mathrm{CF}_{3} \mathrm{Br}$ [39].

Over the energy range $0.2-0.9 \mathrm{eV}$ (see Fig. 2a), the energy dependence of the cross-section for $\mathrm{SF}_{5}{ }^{-}$formation is well described by a simple exponential decrease $\sigma\left(E ; \mathrm{SF}_{5}{ }^{-}\right) \propto \exp (-E / a)$ with $a=0.246 \mathrm{eV}$. At higher energies, the decrease becomes more rapid as a result of the competing decay of the primary anion complex into $\mathrm{F}^{-}$anions. At about $E=1.25 \mathrm{eV}$ the partial cross-section for $\mathrm{F}^{-}$ formation (see Section 4.2) becomes equal to that for $\mathrm{SF}_{5}{ }^{-}$production. Following a minimum at about $2 \mathrm{eV}$, the $\mathrm{SF}_{5}{ }^{-}$yield exhibits a rather broad, near-bell-shaped band towards higher energies with a maximum at $3.6 \mathrm{eV}$. We attribute this higher lying band (which also produces $\mathrm{F}^{-}$anions with almost the same probability, see Section 4.2) to the dissociation of the first excited anion resonance which is of a repulsive nature.

In Fig. 3 we compare the yields for $\mathrm{SF}_{5}{ }^{-}$formation from three different experiments over the energy range $0-4 \mathrm{eV}$. In the two diagrams (a) and (b), the full circles (gray) represent the combined LPA/EXLPA anion yield, taken from Fig. 2. In Fig. 3a we compare with the $\mathrm{SF}_{5}{ }^{-}$yield measured with the Belfast TEM-TOF apparatus (open circles). From these data we constructed a joint cross-section for $\mathrm{SF}_{5}{ }^{-}$formation by combining the LPA/EXLPA cross-section with the Belfast data for $E \geq 2.2 \mathrm{eV}$ through a brief interpolation (broken curve) from 1.6-2.2 eV. This interpolation and the resolution of the Belfast data were chosen in such a way that the convolution of the joint cross-section with a Gaussian resolution function of $370 \mathrm{meV}$ (FWMH) resulted in a close reproduction (full curve) of the Belfast data over the full energy range. We note that the energy scale of the Belfast data was adjusted so as to match optimally that of the convoluted spectrum. Note that the rather low resolution of the 


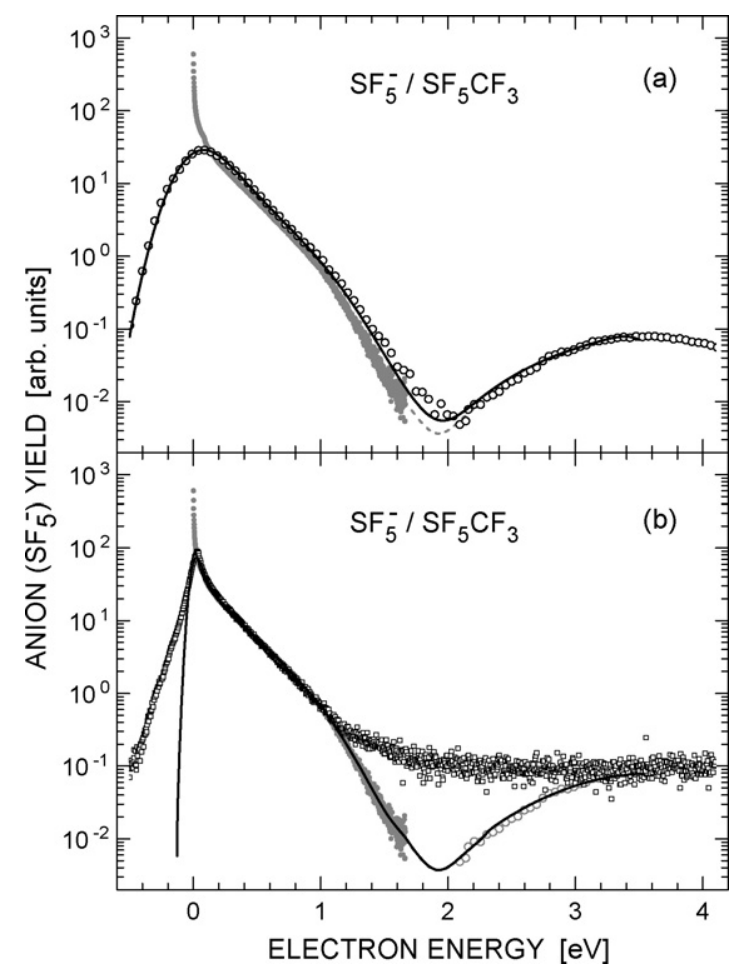

Fig. 3. Comparison of the highly resolved LPA/EXLPA yield for $\mathrm{SF}_{5}{ }^{-}$formation with (a) the TEM-TOF results (Belfast), and (b) the TEM-QMS results (Innsbruck [17]). For details see text.

Belfast experiment introduces substantial deviations of the measured anion yield function from the true DEA cross-section only in energy ranges where sharp features are present, notably at very low energies.

In Fig. 3b, we compare the $\mathrm{SF}_{5}{ }^{-}$anion yield reported by the Innsbruck group [17] (open squares, quoted resolution $80 \mathrm{meV}$ ) with the yield (full curve), obtained by convolution of our joint crosssection with a Gaussian of $80 \mathrm{meV}$ (FWHM). The energy scale of the Innsbruck data was adjusted such as to optimally match that of the convoluted spectrum. Over the range $0.1-1 \mathrm{eV}$, good agreement is observed between the two absolute cross-sections (the absolute scale of the Innsbruck cross-section was established with reference to the total cross-section reported by Chen et al. [19]; the latter work will be discussed below in connection with Fig. 6). At near-zero energies the Innsbruck yield surpasses the convoluted spectrum by about $20 \%$. This observation may be explained by the effects of an increased electron path at the lowest energies, due to helical motion and/or multiple traversals through the attachment region. At the higher energies, the Innsbruck data stay above the LPA/EXLPA cross-section as well as above that measured in Belfast. They do not show the second maximum for $\mathrm{SF}_{5}{ }^{-}$formation, clearly observed in the Belfast experiment around $3.6 \mathrm{eV}$. It appears that the Innsbruck data have a lower dynamical range than the other two data sets; possibly, they are influenced towards higher nominal energies by contributions from low-energy electrons which may be produced, e.g., by scattering from orifices. In our EXLPA work, we found it very important to align the electron source carefully and thus avoid any collisions of the accelerated and decelerated electrons with any of the collimating, potentialdefining orifices. Finally, we note that the $\mathrm{SF}_{5}{ }^{-}$yield measured at Berlin [18] is in qualitative agreement with the Innsbruck data, but has less statistical quality; it also misses the second peak around $3.6 \mathrm{eV}$.

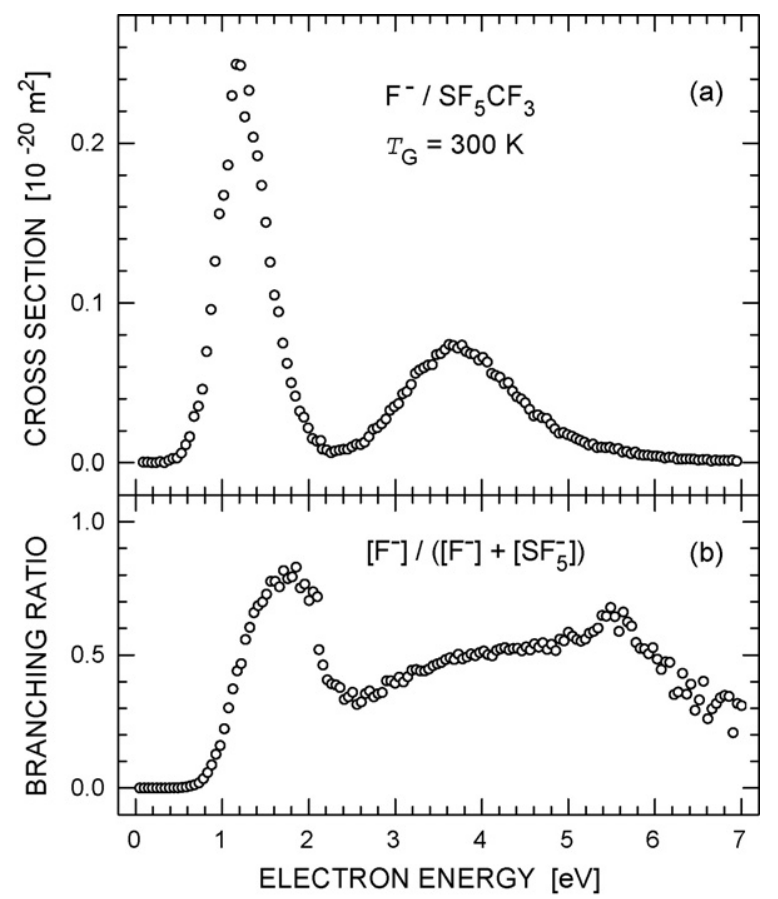

Fig. 4. (a) Absolute cross-section for $\mathrm{F}^{-}$formation due to electron attachment to $\mathrm{SF}_{5} \mathrm{CF}_{3}\left(T_{\mathrm{G}} \approx 300 \mathrm{~K}\right)$ and $(\mathrm{b})$ anion branching ratio $R(E)=\sigma\left(\mathrm{F}^{-}\right) /\left[\sigma\left(\mathrm{F}^{-}\right)+\sigma\left(\mathrm{SF}_{5}^{-}\right)\right]$, both over the energy range $0-7 \mathrm{eV}$.

\subsection{Absolute cross-section for $F^{-}$formation}

In Fig. 4a, we present the absolute partial cross-section for $\mathrm{F}^{-}$ formation over the range $0-7 \mathrm{eV}$. The energy calibration of this spectrum is fixed with reference to the simultaneously taken $\mathrm{SF}_{5}{ }^{-}$ spectrum for which the energy scale is derived from that of the LPA/EXLPA spectrum (Fig. 3a). At energies above about $0.4 \mathrm{eV}$, the $\mathrm{F}^{-}$ yield surpasses the noise level, exhibits a first maximum at $E=1.2 \mathrm{eV}$ with a cross-section $\sigma\left(E=1.2 \mathrm{eV} ; \mathrm{F}^{-}\right) \approx 0.25 \times 10^{-20} \mathrm{~m}^{2}$ which is followed by a minimum around $2.3 \mathrm{eV}$ and a second maximum located at about $3.7 \mathrm{eV}$ with a cross-section of $0.07 \times 10^{-20} \mathrm{~m}^{2}$. As explained in section $3.1, \mathrm{~F}^{-}$formation from $\mathrm{SF}_{5} \mathrm{CF}_{3}$ is an endothermic process. From the energy for the resolution-corrected threshold in Fig. 4a (estimated as $0.6 \mathrm{eV}$ ), and assuming that this threshold is shifted to lower energies from the true onset by the average rovibrational energy in the $\mathrm{SF}_{5} \mathrm{CF}_{3}$ molecule at $300 \mathrm{~K}(0.21 \mathrm{eV})$, one obtains an estimate of $4.2 \mathrm{eV}$ for the separation energy of $\mathrm{F}$ from $\mathrm{SF}_{5} \mathrm{CF}_{3}$.

The first maximum in the $\mathrm{F}^{-}$yield, located at $1.2 \mathrm{eV}$, is attributed to the combination of two effects: (i) the primary attachment process occurs via the lowest-lying anion resonance which is also responsible for $\mathrm{SF}_{5}{ }^{-}$formation at low energies; (ii) dissociation of this primary negative ion state to the energetically accessible channels, yielding $\mathrm{SF}_{5}{ }^{-}$and $\mathrm{F}^{-}$anions, proceeds with a characteristic energy-dependent branching ratio $R(E)=\sigma\left(\mathrm{F}^{-}\right) /\left[\sigma\left(\mathrm{F}^{-}\right)+\sigma\left(\mathrm{SF}_{5}{ }^{-}\right)\right]$, reflecting the channel-specific fragmentation probabilities $p\left(\mathrm{~F}^{-}\right)$ and $p\left(\mathrm{SF}_{5}{ }^{-}\right)$. These probabilities depend on the total energy of the primary anion and on the asymptotic energies of the respective dissociated fragment pairs. They may be obtained from unimolecular decay theory (including the energy-dependent autodetachment process), see the recent work by Troe et al. on the energy dependent branching ratio $\mathrm{SF}_{5}{ }^{-} /\left(\mathrm{SF}_{5}{ }^{-}+\mathrm{SF}_{6}{ }^{-}\right)$resulting from electron attachment to $\mathrm{SF}_{6}$ [27].

In Fig. 4b we present the energy-dependent branching ratio $R(E)$ over the range $0-7 \mathrm{eV}$. From 0.6 to $1.8 \mathrm{eV}$ (i.e., within the 
first anion resonance) the ratio monotonically rises from zero to a maximum value of $80 \%$. Towards higher energies, the second anion resonance first starts to influence and then dominates the branching ratio which attains an average value of about 0.5 in the range around the center of the second anion resonance (3.6 eV).

In Fig. 4a, we did not compare with the results reported previously for $\mathrm{F}^{-}$formation $[17,18]$. These earlier data show some clear deviations from our results. The Innsbruck group reported a broad band for $\mathrm{F}^{-}$production peaking at about $0.9 \mathrm{eV}$ with a peak cross-section of $0.08 \times 10^{-20} \mathrm{~m}^{2}$ which presumably corresponds to the band which we observe to peak at $1.2 \mathrm{eV}$ with a maximum cross-section of $0.25 \times 10^{-20} \mathrm{~m}^{2}$. In addition, a weaker maximum at near-zero energies was observed (Fig. 3 in Ref. [17]); this peak must be due to secondary reactions, as discussed, e.g., in DEA work on $\mathrm{C}_{2} \mathrm{Cl}_{4}$ by the Innsbruck group [43]. The Berlin group [18] reported a rather broad band for $\mathrm{F}^{-}$production, peaking at about $0.5 \mathrm{eV}$ and a substantially weaker and wide band around $3.2 \mathrm{eV}$. For unclear reasons, these two bands are shifted to lower energies by about 0.7 and $0.5 \mathrm{eV}$, respectively, relative to those observed in the present work.

\subsection{Absolute cross-sections for formation of the anions $\mathrm{CF}_{3}{ }^{-}$, $\mathrm{SF}_{4}^{-}$, and $\mathrm{SF}_{3}^{-}$}

In Fig. 5, we summarize the absolute partial cross-sections for the five notable fragment anions, as observed in $\mathrm{DEA}$ to $\mathrm{SF}_{5} \mathrm{CF}_{3}$ over the energy range $0-12 \mathrm{eV}$. In both the $\mathrm{SF}_{5}{ }^{-}$and the $\mathrm{F}^{-}$channel, a



Fig. 5. Partial absolute cross-sections for DEA to $\mathrm{SF}_{5} \mathrm{CF}_{3}(E=0-12 \mathrm{eV})$, yielding the fragment anions: (a) $\mathrm{SF}_{5}{ }^{-}$, (b) $\mathrm{F}^{-}$, (c) $\mathrm{CF}_{3}{ }^{-}$, (d) $\mathrm{SF}_{4}{ }^{-}$, and (e) $\mathrm{SF}_{3}{ }^{-}$. weak band is found around $11 \mathrm{eV}$ in addition to those observed around $3.6 \mathrm{eV}$ and below $2 \mathrm{eV}$. The anions $\mathrm{CF}_{3}{ }^{-}, \mathrm{SF}_{4}{ }^{-}$, and $\mathrm{SF}_{3}{ }^{-}$are formed with small cross-sections (below $3 \times 10^{-23} \mathrm{~m}^{2}$ ).

The Belfast cross-section for $\mathrm{CF}_{3}{ }^{-}$formation has a first rise above the noise level at about $2.7 \mathrm{eV}$ and exhibits two broad bands with maxima at about $4 \mathrm{eV}$ and $8.5 \mathrm{eV}$. The earlier results for the anion $\mathrm{CF}_{3}$ - deviate substantially from the present cross-section and must have been influenced by systematic errors. The $\mathrm{CF}_{3}{ }^{-}$data, reported by Sailer et al. [17] over the range $0-3 \mathrm{eV}$, show a single broad band with a first rise near $0.4 \mathrm{eV}$ and a maximum at about $1.1 \mathrm{eV}$. This finding is in conflict with the estimated endothermicity for $\mathrm{CF}_{3}-$ formation from $\mathrm{SF}_{5} \mathrm{CF}_{3}(1.3 \mathrm{eV}$, see Section 3.1). We note that the Innsbruck data for $\mathrm{SF}_{5} \mathrm{CF}_{3}$ were taken in the presence of the calibrant gas $\mathrm{CCl}_{4}$ [17]. ${ }^{1}$ The anion $\mathrm{Cl}_{2}{ }^{-}$(with a mass close to that of $\mathrm{CF}_{3}{ }^{-}$) is a fragment resulting from DEA to $\mathrm{CCl}_{4}$ and exhibits a DEA band with a very similar appearance and energy location as compared to that reported for $\mathrm{CF}_{3}{ }^{-}$by Sailer et al. (Fig. 2 in Ref. [17]). We therefore suggest that the $\mathrm{CF}_{3}{ }^{-}$band reported in [17] was in fact due to $\mathrm{Cl}_{2}{ }^{-}$formation from $\mathrm{CCl}_{4}$. The $\mathrm{CF}_{3}{ }^{-}$data, reported by Balog et al. [18] over the range $0-4.7 \mathrm{eV}$, exhibit a rather narrow peak at $0 \mathrm{eV}$ and a broad band with a maximum at about $3.5 \mathrm{eV}$. The latter band appears to correspond to our band peaking around $4 \mathrm{eV}$. The peak at near-zero energy in the $\mathrm{CF}_{3}{ }^{-}$yield must have been caused by an experimental artefact (probably by secondary reactions).

DEA cross-sections for the weak fragment anions $\mathrm{SF}_{4}{ }^{-}$(Fig. 5d) and $\mathrm{SF}_{3}{ }^{-}$(Fig. 5e) are reported here for the first time. $\mathrm{SF}_{4}{ }^{-}$formation is characterized by a clear band centered at about $5.7 \mathrm{eV} . \mathrm{SF}_{3}{ }^{-}$ production becomes noticeable at energies above about $8 \mathrm{eV}$ and shows a maximum at about $11.1 \mathrm{eV}$, i.e., $1.7 \mathrm{eV}$ below the adiabatic ionization energy of $\mathrm{SF}_{5} \mathrm{CF}_{3}$ [44].

Using the absolute cross-sections shown in Fig. 5, we determined energy-integrated cross-sections for the five anions over the respective characteristic bands and in this way obtained bandspecific branching ratios. In Table 1 we list the energy location of the maximum of the respective band, the measured FWMH of the band, the integration range, the integrated cross-section (in $10^{-20} \mathrm{~m}^{2} \mathrm{eV}$ ), and the branching ratio in two different forms, namely as the ratio of the integrated cross-sections and as the ratio of the band maxima, both normalized to $100 \%$ for the second band of $\mathrm{SF}_{5}{ }^{-}$(integration window $2.09-6.99 \mathrm{eV}$ ). The branching ratios of the band integrals should be independent of the experimental resolution, see the integrals in Table 1 for the original LPA data $(0.001-2.09 \mathrm{eV})$ and for the LPA data convoluted with Gaussian resolution functions of 80 and $370 \mathrm{meV}$, respectively. The band integrals are thus especially suitable for comparison with other work. The integral of the Belfast data for the first $\mathrm{SF}_{5}{ }^{-}$band is found to be in close agreement with the integral of the LPA data; in part, this agreement reflects the fact that the Belfast data were matched to the convoluted LPA cross-section at higher energies. The integral of the Innsbruck data is $14.6 \%$ larger than that of the LPA data; part of this difference is due to the fact that the Innsbruck cross-section exceeds the convoluted LPA cross-section near the maximum.

In contrast, the ratios of the band maxima exhibit substantial differences whenever the experimental resolution plays a role (in the present case this is only relevant for the $\mathrm{SF}_{5}{ }^{-}$band extending down to zero energy). Thus it is not advisable to compare such a maximum intensity for a near-zero energy peak with the maximum intensity of (broader) bands at higher energies. In general, authors should quote the energy-integrated anion yield of

\footnotetext{
1 W. Sailer, private communication.
} 
Table 1

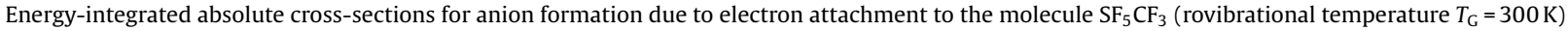

\begin{tabular}{|c|c|c|c|c|c|c|c|}
\hline Anion & Peak position (eV) & $\begin{array}{l}\text { Peak maximum } \\
\left(\times 10^{-20} \mathrm{~m}^{2}\right)\end{array}$ & $\begin{array}{l}\text { Peak width } \\
(\text { FWHM) }(\mathrm{eV})\end{array}$ & $\begin{array}{l}\text { Branching ratio } \\
(\max .)(\times 100)\end{array}$ & $\begin{array}{l}\text { Integration range } \\
(\mathrm{eV})\end{array}$ & Integral $\left(\times 10^{-20} \mathrm{~m}^{2} \mathrm{eV}\right)$ & $\begin{array}{l}\text { Branching ratio } \\
\text { (integral) }(\times 100)\end{array}$ \\
\hline $\mathrm{SF}_{5}^{-}$ & "Zero energy" & & & & & & \\
\hline $\mathrm{LPA}^{\mathrm{a}}$ & 0.001 & 600 & - & - & $0.001-2.09$ & 15.51 & 11,931 \\
\hline$\Delta E_{80}{ }^{\mathrm{b}}$ & 0.025 & 73.8 & 0.13 & 95,359 & $-0.13-2.09$ & 15.51 & 11,931 \\
\hline Innsbr. $^{c}$ & 0.004 & 89.2 & 0.10 & 115,250 & $-0.50-2.09$ & 17.78 & 13,677 \\
\hline$\Delta E_{370}^{\mathrm{d}}$ & 0.082 & 28.8 & 0.46 & 37,209 & $-0.50-2.09$ & 15.51 & 11,931 \\
\hline Belfast $^{\mathrm{e}}$ & 0.082 & 28.8 & 0.47 & 37,209 & $-0.89-2.09$ & 15.65 & 12,043 \\
\hline \multirow[t]{3}{*}{$\mathrm{SF}_{5}-\mathrm{f}$} & 3.53 & 0.0774 & 1.61 & 100.00 & 2.09-6.99 & 0.1300 & 100.00 \\
\hline & 8.31 & 0.0056 & $\approx 1.1$ & 7.24 & 7.19-9.04 & 0.0071 & 5.44 \\
\hline & 10.71 & 0.0167 & $\approx 2.1$ & 21.58 & $9.04-11.83$ & 0.0324 & 24.93 \\
\hline \multirow[t]{4}{*}{$\mathrm{F}^{-\mathrm{f}}$} & 1.19 & 0.2493 & 0.64 & 322.14 & $0.38-2.26$ & 0.1734 & 133.39 \\
\hline & 3.70 & 0.0732 & 1.47 & 94.59 & $2.26-6.99$ & 0.1236 & 95.11 \\
\hline & $\approx 9$ & 0.0019 & - & 2.44 & $7.58-9.53$ & 0.0033 & 2.56 \\
\hline & 11.19 & 0.0090 & $\approx 1.5$ & 11.64 & $9.53-11.23$ & 0.0124 & 9.52 \\
\hline \multirow[t]{3}{*}{$\mathrm{CF}_{3}{ }^{-\mathrm{f}}$} & 4.01 & 0.00105 & $\approx 1.1$ & 1.35 & $2.69-4.75$ & 0.00123 & 0.95 \\
\hline & 5.38 & 0.00072 & $\approx 1.5$ & 0.94 & $4.75-6.99$ & 0.00096 & 0.74 \\
\hline & 8.56 & 0.00101 & $\approx 1.5$ & 1.30 & $6.99-10.02$ & 0.00156 & 1.20 \\
\hline \multirow[t]{3}{*}{$\mathrm{SF}_{4}^{-\mathrm{f}}$} & 5.67 & 0.00289 & $\approx 1.5$ & 3.74 & $3.57-7.33$ & 0.00447 & 3.44 \\
\hline & 8.75 & 0.00036 & - & 0.47 & $7.33-9.58$ & 0.00051 & 0.39 \\
\hline & 11.44 & 0.00052 & - & 0.68 & $9.58-11.83$ & 0.00050 & 0.39 \\
\hline \multirow[t]{2}{*}{$\mathrm{SF}_{3}-\mathrm{f}$} & $\approx 9$ & 0.00040 & - & 0.52 & $7.33-9.58$ & 0.00046 & 0.36 \\
\hline & 11.1 & 0.00153 & $\approx 1.3$ & 1.97 & $9.58-11.83$ & 0.00190 & 1.46 \\
\hline
\end{tabular}

a Peak position and maximum are given for $E=1 \mathrm{meV}$ (the cross-section is divergent for $E \rightarrow 0$ ).

b LPA cross-section convoluted with Gaussian energy resolution function of FWHM $=80 \mathrm{meV}$ (see Fig. 3b).

c Data of the Innsbruck group [17] (see Fig. 3b).

d LPA cross-section convoluted with Gaussian energy resolution function of FWHM $=370 \mathrm{meV}$ (see Fig. 3a).

e Data of the Belfast experiment (see Fig. 3a).

${ }^{f}$ Data of the Belfast experiment (see Fig. 5).

observed DEA bands, but we consider it mandatory that energyintegrated (absolute or relative) cross-sections are provided for narrow, resolution-limited bands, especially for the band extending down to zero energy.

We emphasize that maximum intensities for near-zero energy peaks, measured with decelerated electron beams (with or without a magnetic guiding field) are often questionable for various reasons. In the absence of a guiding magnetic field, it is nearly impossible to reach near-zero kinetic energies in a controlled way. In the presence of a guiding magnetic field, transverse velocity components prevent the range close to zero kinetic energy being accessed; moreover, electron spiralling effects introduce uncertainties in the path length and thus in the anion yield. Even if transverse components are ruled out or reduced (as in the EXLPA experiment in which the photoelectrons are formed with zero kinetic energy), there is still the uncertainty whether the electrons are decelerated to near-zero energy in the proper reaction volume and whether the electrons traverse this volume only once. In our opinion, the only trustworthy, presently available approach to reliably measure the shape of DEA cross-sections at energies below about $50 \mathrm{meV}$ is the laser photoelectron attachment experiment in which monoenergetic electrons with variable kinetic energy undergo attachment reactions in essentially the same (nearly) field-free volume in which they are formed by photoionization.

\subsection{Total DEA cross-section and the dependence of the DEA rate coefficient on electron temperature}

Summation of the five partial absolute DEA cross-sections in Fig. 5 yields the total absolute DEA cross-section $\sigma_{\text {tot }}(E)$ for $\mathrm{SF}_{5} \mathrm{CF}_{3}$, shown as the full curve in Fig. 6. For comparison, we included the partial cross-sections for $\mathrm{SF}_{5}{ }^{-}$(open circles) and $\mathrm{F}^{-}$formation (open squares), and the sum cross-section for the formation of $\mathrm{CF}_{3}{ }^{-}$,
$\mathrm{SF}_{4}{ }^{-}$, and $\mathrm{SF}_{3}{ }^{-}$(full diamonds). Note that these data were obtained at the fixed gas temperature $T_{\mathrm{G}}=300 \mathrm{~K}$.

In Fig. 6, we also included the total cross-section for anion production (open triangles), reported by Chen et al. for a target gas temperature $T_{\mathrm{G}} \approx 300 \mathrm{~K}$ (see Fig. 2 in Ref. [19]). These authors used a magnetically guided electron beam (monochromatized to an effective energy width of about $80 \mathrm{meV}$ by the retarding-potentialdifference method) and measured the total anion current formed.

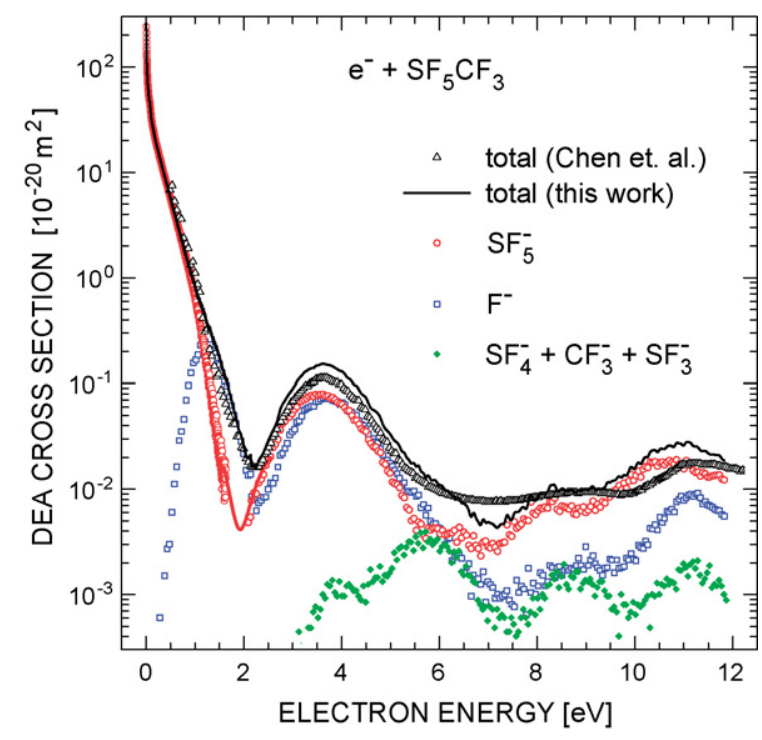

Fig. 6. Total and partial absolute cross-sections for anion formation in electron$\mathrm{SF}_{5} \mathrm{CF}_{3}$ collisions (gas temperature $T_{\mathrm{G}}=300 \mathrm{~K}$ ). Total cross-section, full curve (present work) and open triangles (Chen et al. [19]); $\mathrm{SF}_{5}{ }^{-}$, open circles; $\mathrm{F}^{-}$, open squares; sum of $\mathrm{CF}_{3}{ }^{-}, \mathrm{SF}_{4}{ }^{-}$, and $\mathrm{SF}_{3}{ }^{-}$, full diamonds. 
The electron energy and the cross-section for $\mathrm{SF}_{5} \mathrm{CF}_{3}$ were placed on absolute scales, respectively, with reference to measurements with the target molecule $\mathrm{N}_{2} \mathrm{O}$, using the absolute attachment crosssection for $\mathrm{N}_{2} \mathrm{O}$ obtained by Rapp and Briglia [45]. Very good overall agreement is observed between the total cross-section reported by Chen et al. [19] and that obtained in the present work by a different method, both with regard to the absolute size of the crosssections and the energy locations of the main bands. We note that the Chen et al. data shown in Fig. 6 were obtained by digitizing the results in their Fig. 2; in view of the $0.08 \mathrm{eV}$ resolution and the steepness of the plot near zero energy we did not include data points at energies below $0.5 \mathrm{eV}$. At energies above $6.5 \mathrm{eV}$, where the total cross-section stays below $3 \times 10^{-22} \mathrm{~m}^{2}$, the two sets of cross-sections differ from each other by no more than a factor of two.

In the following, we discuss the dependence of the total DEA rate coefficient $k\left(T_{\mathrm{e}} ; T_{\mathrm{G}}\right)$ on electron temperature $T_{\mathrm{e}}$ for the fixed gas temperature $T_{\mathrm{G}}=300 \mathrm{~K}$. We calculate $k\left(T_{\mathrm{e}} ; T_{\mathrm{G}}\right)$ with (1), using the total DEA cross-section in Fig. 6 and a Maxwellian electron distribution function. The latter choice appears well justified for the recent drift-tube experiment of Mayhew et al. [16] in which $\mathrm{CO}_{2}$ was used as the carrier gas at atmospheric pressure and room temperature $\left(T_{\mathrm{e}}=T_{\mathrm{G}}=300 \mathrm{~K}\right)$. Carbon dioxide is known to rapidly establish Maxwellian equilibrium for the electron distribution function. In the earlier measurements of Kennedy and Mayhew [7] in which the mean electron energy $\langle E\rangle$ was varied from 0.04 to $1.9 \mathrm{eV}$, the carrier gas $\mathrm{N}_{2}$ was used for $\langle E\rangle<0.5 \mathrm{eV}$, and $\mathrm{Ar}$ for $\langle E\rangle>0.5 \mathrm{eV}$.

In Fig. 7, we compare the rate coefficient $k\left(T_{e} ; T_{G}=300 \mathrm{~K}\right)$, calculated with the new total absolute DEA cross-section over the range $T_{\mathrm{e}}=50-20,000 \mathrm{~K}$ (i.e., mean electron energy $\left.\langle E\rangle=(3 / 2) k_{\mathrm{B}} T_{\mathrm{e}}=0.0065-2.6 \mathrm{eV}\right)$, with the temperature dependence reported by Kennedy and Mayhew [7]. Good overall agreement between the two data sets is observed over the broad temperature range covered in the experiment. Note that for the buffer gases $\mathrm{N}_{2}$ and $\mathrm{Ar}$ the electron distribution function in this drift tube experiment will deviate from the Maxwellian form assumed in the calculations. The relatively small differences between the measured and calculated rate coefficients will therefore in part be due to deviations of the experimental electron distribution function from the Maxwellian form. The calculated rate coefficient $k\left(T_{\mathrm{e}} ; T_{\mathrm{G}}=300 \mathrm{~K}\right)$ is identically recovered up to electron temperatures $T_{\mathrm{e}}=800 \mathrm{~K}(\langle E\rangle=0.103 \mathrm{eV})$ when the partial DEA cross-section for $\mathrm{SF}_{5}{ }^{-}$formation is used instead of the total cross-section. At

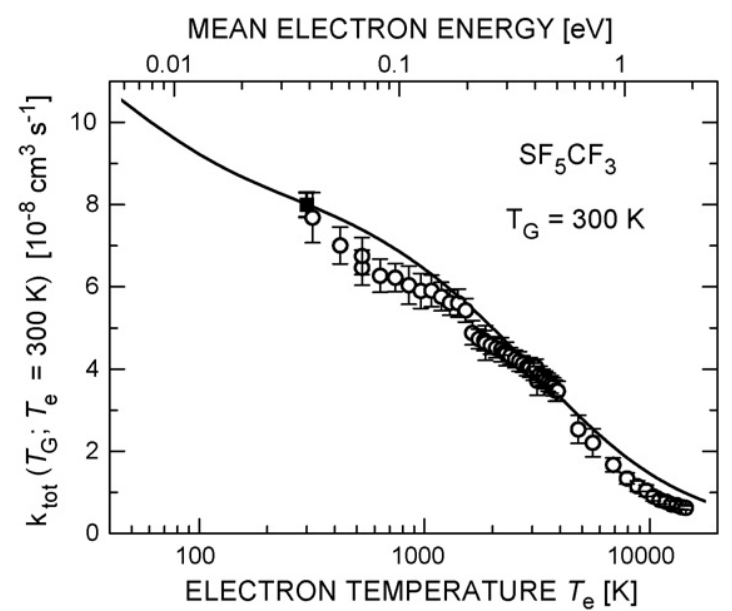

Fig. 7. Dependence of the total rate coefficient for $\mathrm{DEA}$ to $\mathrm{SF}_{5} \mathrm{CF}_{3}$ on electron temperature $T_{\mathrm{e}}$ over the range of $50-20,000 \mathrm{~K}$ at the fixed gas temperature $T_{\mathrm{G}}=300 \mathrm{~K}$.
$T_{\mathrm{e}}=12000 \mathrm{~K}(\langle E\rangle=1.551 \mathrm{eV})$, the rate coefficient for $\mathrm{SF}_{5}{ }^{-}$formation still amounts to $95 \%$ of the total rate coefficient.

\section{Conclusions}

Partial and total absolute cross-sections for dissociative electron attachment to the molecule trifluoromethyl sulfurpentafluoride $\left(\mathrm{SF}_{5} \mathrm{CF}_{3}\right)$ at the gas temperature $T_{\mathrm{G}}=300 \mathrm{~K}$ are reported over a broad range of electron energies $(E=0.001-12 \mathrm{eV})$. The absolute scale for the cross-sections is determined with reference to the thermal $(T=300 \mathrm{~K})$ rate coefficient for anion formation $\left(8.0(3) \times 10^{-8} \mathrm{~cm}^{3} \mathrm{~s}^{-1}\right)$.

Below $1 \mathrm{eV}, \mathrm{SF}_{5}{ }^{-}$is the dominant product anion and formed through the lowest anion state which cuts the neutral $\mathrm{SF}_{5} \mathrm{CF}_{3}$ potential close to the $\mathrm{S}-\mathrm{C}$ equilibrium distance. The highly resolved laser photoelectron attachment data exhibit a downward Wigner cusp at $86 \mathrm{meV}$, indicating that the $v_{4}\left(a_{1}\right)$ vibrational mode is important for the primary attachment dynamics. Semiempirical R-matrix calculations of the energy dependent cross-section for $\mathrm{SF}_{5}{ }^{-}$formation yield good agreement with the experimental DEA cross-section, but cannot reproduce the activation energy for the thermal DEA rate coefficient observed in a swarm experiment.

Both $\mathrm{SF}_{5}{ }^{-}$and $\mathrm{F}^{-}$anions are formed with similar yields through the first excited resonance located near $3.6 \mathrm{eV}$. Towards larger electron energies, the anions $\mathrm{CF}_{3}{ }^{-}, \mathrm{SF}_{4}{ }^{-}$, ands $\mathrm{SF}_{3}{ }^{-}$anions are produced in addition with low cross-sections. Summation of the partial (mass-resolved) cross-sections yielded a total absolute crosssection for anion formation over the energy range $0.001-12 \mathrm{eV}$; the only previously reported total attachment cross-section for $\mathrm{SF}_{5} \mathrm{CF}_{3}$ ( $\left.T_{\mathrm{G}} \approx 300 \mathrm{~K}\right)$, obtained with a different method by Chen et al. [19] at a resolution of about $80 \mathrm{meV}$, is found to be in good agreement with our results. Our highly resolved DEA cross-section is used to calculate the dependence of the rate coefficient for dissociative electron attachment over a broad range of electron temperatures for the fixed gas temperature $T_{\mathrm{G}}=300 \mathrm{~K}$; good agreement is observed between the calculated values and those obtained in a drift tube experiment.

G3(MP2) calculations were carried out to provide information on the reaction energetics. Molecular geometries and energies are available through the journal as a Supplementary file.

\section{Acknowledgements}

This cooperative work has been stimulated by the ESF Network EIPAM (electron induced processing at the molecular level). The work at Kaiserslautern has been supported by the Deutsche Forschungsgemeinschaft (HO 427/29) and by the Research Center OTLAP. K.G. would like to thank the European Social Fund for providing a PhD studentship. T.A.F., K.G. and L.M.G. would like to thank the EPSRC for their support of this work through grant EP/F031025/1. C.A.M. gratefully acknowledges support from ESF (EIPAM) and the EPSRC funded UK Nonthermal Plasma Network for travel grants to the Technische Universität Kaiserslautern and Queen's University Belfast, respectively, and EPSRC. I.I.F. was supported by the US National Science Foundation, Grant PHY-0652866. T.M.M. acknowledges support from the U.S. Air Force Office of Scientific Research. We thank W. Sailer and R. Balog for providing their DEA data in numerical form. One of us (H.H.) gratefully acknowledges helpful correspondence and discussions with W. Sailer.

\section{Appendix A. Supplementary data}

Supplementary data associated with this article can be found, in the online version, at doi:10.1016/j.ijms.2008.05.022. 


\section{References}

[1] W.T. Sturges, T.J. Wallington, M.D. Hurley, K.P. Shine, K. Sihra, A. Engel, D.E. Oram, S.A. Penkett, R. Mulvaney, C.A.M. Brenninkmeijer, Science 289 (2000) 611.

[2] L. Huang, L. Zhu, X. Pan, J. Zhang, B. Ouyang, H. Hou, Atmos. Environ. 39 (2005) 1641.

[3] W.-T. Tsai, J. Fluorine Chem. 128 (2007) 1345.

[4] W.-T. Tsai, J. Hazard. Mater. 149 (2007) 747.

[5] P.A. Kendall, N.J. Mason, G.A. Buchanan, G. Marston, P. Tegeder, A. Dawes, S. Eden, P. Limão-Vieira, D.A. Newnham, Chem. Phys. 287 (2003) 137.

[6] P. Limão-Vieira, S. Eden, P.A. Kendall, N.J. Mason, A. Giuliani, J. Heinesch, M.-J. Hubin-Franskin, J. Delwiche, S.V. Hoffmann, Int. J. Mass Spectrom. 233 (2004) 335.

[7] R.A. Kennedy, C.A. Mayhew, Int. J. Mass Spectrom. 206 (2001) i-iv

[8] T.M. Miller, S.T. Arnold, A.A. Viggiano, W.B. Knighton, J. Chem. Phys. 116 (2002) 6021.

[9] T. Takahashi, T. Nakayama, Y. Matsumi, S. Solomon, T. Gejo, E. Shigemasa, T.J Wallington, Geophys. Res. Lett. 29 (2002) 7/1

[10] R.Y.L. Chim, R.A. Kennedy, R.P. Tuckett, Chem. Phys. Lett. 369 (2003) 697.

[11] L.G. Christophorou, J.K. Olthoff, J. Phys. Chem. Ref. Data 29 (2000) 267.

[12] L.G. Christophorou, J.K. Olthoff, Fundamental Electron Interactions with Plasma Processing Gases, Kluwer Academic/Plenum Publ., New York, 2004.

[13] M. Braun, M.-W. Ruf, H. Hotop, P. Cicman, P. Scheier, T.D. Märk, E. Illenberger, R.P. Tuckett, C.A. Mayhew, Int. J. Mass Spectrom. 252 (2006) 234.

[14] O.J. Nielsen, F.M. Nicolaisen, C. Bacher, M.D. Hurley, T.J. Wallington, K.P. Shine, Atmos. Environ. 36 (2001) 1237.

[15] C.P. Rinsland, S.W. Sharpe, R.L. Sams, J. Quant. Spectrosc. Radiat. Transfer 82 (2003) 483.

[16] C.A. Mayhew, A.D.J. Critchley, D.C. Howse, V. Mikhailov, M.A. Parkes, Eur. Phys. J. D 35 (2005) 307.

[17] W. Sailer, H. Drexel, A. Pelc, V. Grill, N.J. Mason, E. Illenberger, J.D. Skalny, T. Mikoviny, P. Scheier, T.D. Märk, Chem. Phys. Lett. 351 (2002) 71.

[18] R. Balog, M. Stano, P. Limao-Vieira, C. König, I. Bald, N.J. Mason, E. Illenberger, J. Chem. Phys. 119 (2003) 10396.

[19] C.L. Chen, R.E. Wootton, P.J. Chantry, Proceedings of the Seventh International Conference on Gas Discharges and their Applications, London, England (Peregrinus, London), 1982, p. 321.

[20] D. Klar, M.-W. Ruf, H. Hotop, Aust. J. Phys. 45 (1992) 263.

[21] J.M. Weber, E. Leber, M.-W. Ruf, H. Hotop, Eur. Phys. J. D 7 (1999) 587.

[22] M. Braun, S. Barsotti, S. Marienfeld, E. Leber, J.M. Weber, M.-W. Ruf, H. Hotop, Eur. Phys. J. D 35 (2005) 177.

[23] T.A. Field, A.E. Slattery, D.J. Adams, D.D. Morrison, J. Phys. B 38 (2005) 255

[24] L.A. Curtiss, P.C. Redfern, K. Raghavachari, V. Rassolov, J.A. Pople, J. Chem. Phys. 110 (1999) 4703.
[25] M.J. Frisch, G.W. Trucks, H.B. Schlegel, G.E. Scuseria, M.A. Robb, J.R. Cheese man, J.A. Montgomery Jr., T. Vreven, K.N. Kudin, J.C. Burant, J.M. Millam, S.S. Iyengar, J. Tomasi, V. Barone, B. Mennucci, M. Cossi, G. Scalmani, N. Rega, G.A. Petersson, H. Nakatsuji, M. Hada, M. Ehara, K. Toyota, R. Fukuda, J. Hasegawa, M. Ishida, T. Nakajima, Y. Honda, O. Kitao, H. Nakai, M. Klene, X. Li, J.E. Knox, H.P. Hratchian, J.B. Cross, V. Bakken, C. Adamo, J. Jaramillo, R. Gomperts, R.E. Stratmann, O. Yazyev, A.J. Austin, R. Cammi, C. Pomelli, J.W. Ochterski, P.Y. Ayala, K. Morokuma, G.A. Voth, P. Salvador, J.J. Dannenberg, V.G. Zakrzewski, S. Dapprich, A.D. Daniels, M.C. Strain, O. Farkas, D.K. Malick, A.D. Rabuck, K. Raghavachari, J.B. Foresman, J.V. Ortiz, Q. Cui, A.G. Baboul, S. Clifford, J. Cioslowski, B.B. Stefanov, G. Liu, A. Liashenko, P. Piskorz, I. Komaromi, R.L. Martin, D.J. Fox, T. Keith, M.A. Al-Laham, C.Y. Peng, A. Nanayakkara, M. Challacombe, P.M.W. Gill, B. Johnson, W. Chen, M.W. Wong, C. Gonzalez, J.A. Pople, Gaussian 03 Revision C. 02, Gaussian, Inc., Wallingford, CT, 2004.

[26] J.A. Ruiz, A. Kivimäki, M. Stankiewicz, E.M. Garcia, M. Coreno, S. Ali, J. Koperski, E. Rachlew, G.V.i Serrano, V. Feyer, R. Tuckett, Phys. Chem. Chem. Phys. 8 (2006) 5199.

[27] J. Troe, T.M. Miller, A.V. Viggiano, J. Chem. Phys. 127 (2007) 244304

[28] W. Tsang, J.T. Herron, J. Chem. Phys. 96 (1992) 4272

[29] H.-J. Deyerl, L.S. Alconcel, R.E. Continetti, J. Phys. Chem. A 105 (2001) 552

[30] C. Blondel, C. Delsart, F. Goldfarb, J. Phys. B 34 (2001) L281.

[31] D.F. Eggers Jr., H.E. Wright, D.W. Robinson, J. Chem. Phys. 35 (1961) 1045.

[32] Z. Li, J. Yang, J.G. Hou, Q. Zhu, Chem. Phys. Lett. 359 (2002) 321.

[33] I.I. Fabrikant, H. Hotop, M. Allan, Phys. Rev. A 71 (2005) 022712

[34] A.M. Lane, R.G. Thomas, Rev. Mod. Phys. 30 (1958) 257.

[35] I.I. Fabrikant, Phys. Rev. A 43 (1991) 3478.

[36] S.A. Kalin, A.K. Kazansky, J. Phys. B 23 (1990) 4377.

[37] M.S. Malmberg, A.A. Maryott, J. Chem. Phys. 53 (1970) 1614

[38] D. Klar, M.-W. Ruf, H. Hotop, Int. J. Mass Spectrom. 205 (2001) 93.

[39] S. Marienfeld, T. Sunagawa, I.I. Fabrikant, M. Braun, M.-W. Ruf, H. Hotop, J. Chem. Phys. 124 (2006) 154316.

[40] S. Marienfeld, I.I. Fabrikant, M. Braun, M.-W. Ruf, H. Hotop, J. Phys. B 39 (2006 105.

[41] I.I. Fabrikant, H. Hotop, Phys. Rev. A 63 (2001) 1, 022706.

[42] H. Hotop, M.-W. Ruf, M. Allan, I.I. Fabrikant, Adv. Atom. Mol. Opt. Phys. 49(2003) 85.

[43] H. Drexel, W. Sailer, V. Grill, P. Scheier, E. Illenberger, T.D. Märk, J. Chem. Phys. 118 (2003) 7394

[44] D.M.P. Holland, D.A. Shaw, I.C. Walker, I.J. McEwen, E. Aprà, M.F. Guest, J. Phys B 38 (2005) 2047.

[45] D. Rapp, D.D. Briglia, J. Chem. Phys. 43 (1965) 1480. 